\title{
Stimulasi Bermain Di Ruang PUblik TerPadu RAMah ANAK (RPTRA)_HaRaPan Mulya, Kemayoran , Jakarta PuSAT \\ ${ }^{1}$ Yusnita Mahmur, ${ }^{2}$ Sophianita T. Amany
}

\author{
${ }^{1}$ Fakultas Kedokteran, Universitas YARSI, \\ Jln Letjen Suprapto Cempaka Putih Jakarta Pusat Telp 021-4244574, \\ email :yusnita@yarsi.ac.id; sophianita@yarsi.ac.id
}

\begin{abstract}
Child protection is a family and community duty. Playing can build children's intelligence, imagination, motor skills, social interaction and emotional development (Davida, 2004). The Child Friendly Integrated Public Space called RPTRA (Ruang Public Terpadu Ramah Anak) is an open space that combines the activities and activities of citizens by implementing 10 (ten) main programs of Family Empowerment and Welfare to integrate with Child Friendly City program. To optimize the function of RPTRA and to stimulate the growth of children under five need to do stimulation of structured play. Community service activities aimed at the preparation of guidelines and skills training for mothers about play stimulation for toddlers. The method undertaken is the preparation of guidelines and skills training. This activity was carried out in Harapan Mulya RPTRA, Harapan Mulya Sub-district, Kemayoran Sub-district, Central Jakarta on February 28, 2017. The result of this activity is knowledge improvement at 100\% (target 70\%) and participants satisfaction at 100\% (target 70\%). One of the obstacles faced is the follow-up monitoring of play stimulation at home by participants. The conclusion of this activity is the increase of participant's knowledge and participant's satisfaction to this activity.
\end{abstract}

Keywords: play stimulation, growth, RPTRA, mother, toddler

\begin{abstract}
Abstrak. Perlindungan anak merupakan tugas keluarga dan masyarakat. Bermain dapat membangun intelegensi anak, imajinasi, kemampuan motorik, interaksi sosial dan perkembangan emosi (Davida, 2004). Ruang Publik Terpadu Ramah Anak (RPTRA) adalah tempat dan/atau ruang terbuka yang memadukan kegiatan dan aktivitas warga dengan mengimplementasikan 10 (sepuluh) program Pokok Pemberdayaan dan Kesejahteraan Keluarga untuk mengintegrasikan dengan program Kota Layak Anak. Untuk mengoptimalkan fungsi RPTRA dan menstimulasi tumbuh kembang anak balita perlu dilakukan stimulasi bermain yang terstruktur. Kegiatan pengabdian masyarakat ini bertujuan penyusunan panduan dan pelatihan keterampilan untuk ibu tentang stimulasi bermain untuk balita. Metode yang dilakukan adalah penyusunan panduan dan pelatihan keterampilan. Kegiatan dilakukan di Ruang Publik Terpadu Ramah Anak Harapan Mulia, Kelurahan Harapan Mulia, Kecamatan Kemayoran, Jakarta Pusat pada tanggal 28 Februari 2017. Hasil dari kegiatan ini adalah adanya peningkatan pengetahuan pada $100 \%$ (target 70\%) dan angka kepuasan peserta $100 \%$ dari target $70 \%$. Salah satu kendala yang dihadapi adalah pemantaun tindak lanjut stimulasi bermain di rumah oleh peserta. Kesimpulan dari kegiatan ini adanya peningkatan pengetahuan peserta dan kepuasan peserta terhadap kegiatan ini.
\end{abstract}

Kata kunci: stimulasi bermain, tumbuh kembang, RPTRA, ibu, balita 


\section{Pendahuluan}

Undang-Undang no. 23 tahun 2002 tentang perlindungan anak menyatakan bahwa anak adalah tunas, potensi, dan generasi muda penerus cita-cita perjuangan bangsa, memiliki peran strategis dan mempunyai ciri dan sifat khusus yang menjamin kelangsungan eksistensi bangsa dan negara pada masa depan. Agar setiap anak kelak mampu memikul tanggung jawab tersebut, maka ia perlu mendapat kesempatan yang seluas-luasnya untuk tumbuh dan berkembang secara optimal, baik fisik, mental maupun sosial, dan berakhlak mulia, perlu dilakukan upaya perlindungan serta untuk mewujudkan kesejahteraan anak dengan memberikan jaminan terhadap pemenuhan hak-haknya serta adanya perlakuan tanpa diskriminasi (UU No.23 tentang Perlindungan Anak, 2002).

Perlindungan anak ini merupakan tugas keluarga dan masyarakat. Keluarga mempunyai fungsi dalam pengasuhan anak yaitu fungsi biologis, fungsi sosialisasi dan pendidikan, fungsi religius, fungsi perlindungan, fungsi sosialisasi, fungsi kasih sayang, fungsi ekonomis, dan fungsi rekreasi yang akan berperan penting dalam proses pengasuhan anak (Rakhmawati, 2015) .

Perhatian terhadap Anak Usia Dini menjadi penting karena merupakan masa emas (Golden Periode), jendela kesempatan (window opportunity) tetapi juga masa kritis (critical period). Hal ini bermakna, plastisitas otak anak pada masa ini mempunyai sisi positif dan sisi negatif. Sisi positif otak pada masa ini lebih terbuka untuk proses pembelajaran dan pengkayaan, namun sisi negatifnya lebih peka terhadap lingkungan yang tidak mendukung seperti asupan gizi yang tidak adekuat, kurang stimulasi dan tidak mendapatkan pelayanan kesehatan yang memadai (Kemenkes RI, 2010).

Stimulasi adalah upaya orang tua atau keluarga untuk mengajak anak bermain dalam suasana penuh gembira dan kasih sayang. Aktivitas bermain dan suasana cinta ini penting guna merangsang seluruh sistem indera, melatih kemampuan motorik halus dan kasar, kemampuan berkomunikasi serta perasaan dan pikiran anak. Rangsangan atau stimulasi sejak dini adalah salah satu faktor eksternal yang sangat penting dalam menentukan kecerdasan anak. Selain stimulasi, ada faktor eksternal lain yang ikut mempengaruhi kecerdasan seorang anak yakni kualitas asupan gizi, pola pengasuhan yang tepat dan kasih sayang terhadap anak (Soedjatmiko,2008).

Menstimulasi anak usia prasekolah dengan bermain. Bermain secara tidak langsung akan membuat anak mengembangkan kemampuan fisik-motorik, sosial-emosional, dan kognisinya. Pemberian stimulasi tumbuh kembang dapat dilakukan dengan cara bermain . Bermain dapat dilakukan merupakan suatu aktivitas dimana anak dapat melakukan atau mempraktekkan keterampilan, memberikan ekspresi terhadap pemikiran, menjadi kreatif, mempersiapkan diri untuk berperan dan berperilaku dewasa. Bermain dapat membangun intelegensi anak, imajinasi, kemampuan motorik, interaksi sosial dan perkembangan emosi (Davida, 2004).

Ruang bermain anak yang semakin menyempit membuat pemerintah DKI Jakarta membuat terobosan untuk membangun Ruang Publik Terpadu Ramah Anak (RPTRA) di setiap kelurahan. Ruang Publik Terpadu Ramah Anak (RPTRA) adalah tempat dan/atau ruang terbuka yang memadukan kegiatan dan aktivitas warga dengan mengimplementasikan 10 (sepuluh) program Pokok Pemberdayaan dan Kesejahteraan Keluarga untuk mengintegrasikan dengan program Kota Layak Anak (Pergub No.196 Tahun 2015)

Tujuan RPTRA dibangun antara lain untuk menyediakan ruang terbuka untuk memenuhi hak anak agar anak dapat hidup, tumbuh, berkembang dan berpartisipasi secara 
optimal sesuai dengan harkat dan martabat kemanusiaan, menyediakan prasarana dan sarana kemitraan antara Pemerintah Daerah dan masyarakat dalam memenuhi hak anak dan menyediakan prasarana dan sarana kota sebagai Kota Layak Anak (Pergub No.196 Tahun 2015)

Ruang Publik Terpadu Ramah Anak Harapan Mulia diresmikan 1 Juni 2016.

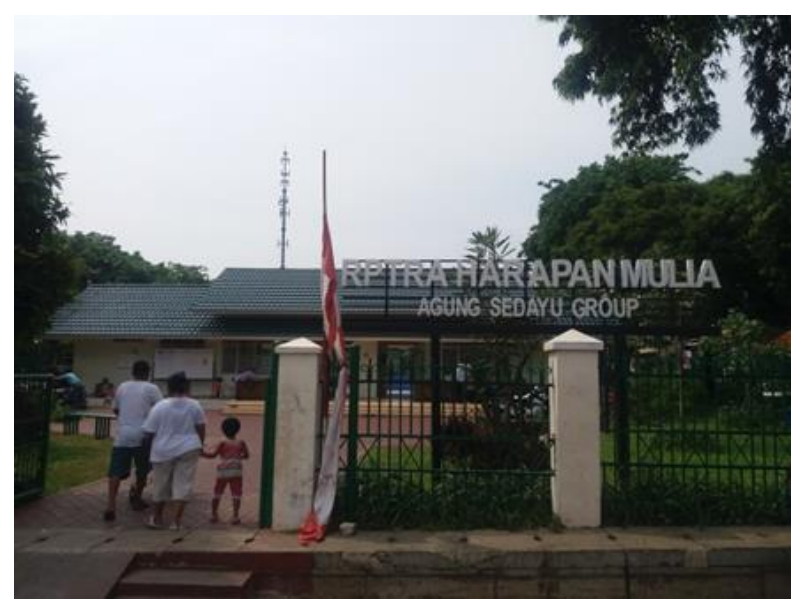

Gambar 1. RPTRA Harapan Mulya

Tahapan keluarga menurut Duvall, keluarga dengan anak pra sekolah berada pada tahap III. Tahap kritis pada tahapan ini adalah adaptasi terhadap kebutuhan anak pra sekolah terhadap stimulasi tumbuh kembang (Mchinney and Freeman, 2009).

Hasil presurvey di RPTRA Harapan Mulya pada bulan Oktober 2016 bahwa kegiatan bermain anak disini sudah dilakukan namun tidak terstruktur, tidak ada jadwal khusus stimulasi tumbuh kembang balita, belum ada sarana khusus permainan edukatif. Kesulitan yang dihadapi. kegiatan kurang teroranisir, anak-anak bermain bebas. Untuk mengoptimalkan fungsi RPTRA dan menstimulasi tumbuh kembang anak balita perlu dilakukan stimulasi bermain yang terstruktur.

Tujuan kegiatan ini adalah menyusun materi panduan untuk ibu tentang stimulasi bermain untuk balita dan meningkatkan keterampilan ibu dalam menstimulasi permainan untuk balita. Manfaat kegiatan ini adalah tersusunnya panduan untuk ibu tentang stimulasi bermain untuk balita dan peningkatan pengetahuan dan keterampilan ibu dalam menstimulasi permainan untuk balita.

\section{Metodologi Pelaksanaan Pengmas}

Metode yang dilakukan pada kegiatan ini adalah penyusunan materi panduan untuk ibu tentang stimulasi bermain untuk balita dan melakukan pelatihan keterampilan ibu dalam menstimulasi permainan untuk balita. Sasaran kegiatan ini adalah Ibu dan balita di lingkungan sekitar RPTRA Harapan Mulya. Sarana dan alat yang digunakan antara lain materi panduan, laptop, in focus, alat permainan. Pihak-pihak yang terlibat adalah kader Bina Keluarga Balita, Pengurus RPTRA dan Suku Dinas PPAPP (Pemberdayaan dan Perlindungan Anak dan Pengendalian Penduduk) Jakarta Pusat. Evaluasi dilakukan dengan ditemukannya peningkatan pengetahuan sebanyak $70 \%$ dari peserta pelatihan dan angka kepuasan peserta sebanyak $70 \%$. 


\section{Hasil dan Pembahasan}

\section{Materi Panduan Stimulasi Bermain}

Materi panduan disusun dengan menjelasakan arti tumbuh kembang dan bagaimana cara pengukuran tumbuh dan kembang. Stimulasi tumbuh kembang dapat dilakukan dengan bermain. Salah satu metode untuk menstimulasi tumbuh kembang adalah dengan metode Montessori yang menstimukasi area keterampilan diri/ life skill, sensori, budaya, Bahasa dan matematika.

Keterampilan hidup / life skill merupakan kegiatan praktis ayng dialkukan orang dewasa dalam kehidupan sehari-hari yang melibatkan anak sehingga anak dapat memelihara lingkungan hidup yang bertujuan agar anak mandiri, konsentrasi, meningkatkan koordinasi dan percaya diri serta kepekaan sosial. Sensori merupakan kegiatan merangsang sensori-motor melalui kelima inderanya untuk memahami konsep baru melalui pengalaman indera dan latihan yang bertujuan membantu anak mencapai kemampuan indera yang maksimal, mengembangkan rentang konsentrasi dan meningkatkan intelegensi.

Peradaban dan Budaya merupakan Area yang membantu anak mengenal dunia atau lingkungan hidup baik yang ada disekitarnya maupun lingkungan yang lebih luas yang bertujuan membantu anak dalam membangun kepribadiannya, beradaptasi dengan budaya lingkungannya. Area Bahasa adalah suatu sistem suara, kata dan pola yang digunakan manusia untuk menyampaikan pikiran dan perasaanna yang membantu anak mengembangkan kemampuan komunikasi dasar,persiapan menulis dan membaca. Area matematika teringterasi dengan area lain. Belajar matematika tidak dimulai dengan anak berhitung atau mengenal angka tetapi dimulai saat anak hidup merasakan keteraturan pola dan ketetapan dalam hidup bertujuan membantu perkembangan kognitif dan membangun kemampuan dalam memcahkan masalah.

Semua stimulasi diatas dilakukan dengan aneka permainan seperti terlihat pada table dibawah ini:

Tabel 1. Stimulasi Bermain dengan Metode Montessori

\begin{tabular}{|c|c|}
\hline Area & Permainan \\
\hline \multirow[t]{5}{*}{ Keterampilan Hidup } & $\begin{array}{l}\text { Tuang dan memindahkan } \\
\text { benda padat, cair }\end{array}$ \\
\hline & Menggunting \\
\hline & Memasangkan \\
\hline & Berjalan diatas garis \\
\hline & Pengenalan menjahit :menganyam \\
\hline \multirow[t]{5}{*}{ Sensori } & Kartu warna \\
\hline & Papan raba \\
\hline & Botol penciuman \\
\hline & Permaianan rasa \\
\hline & Bentuk geometri \\
\hline \multirow[t]{4}{*}{ Peradaban dan Budaya } & Merawat tanaman \\
\hline & Map dunia \\
\hline & $\begin{array}{l}\text { Sains : terapung dan tenggelam, } \\
\text { kaca pemebesar }\end{array}$ \\
\hline & Pengenalan jam \\
\hline \multirow[t]{2}{*}{ Bahasa } & Bernyanyi \\
\hline & Membaca buku \\
\hline
\end{tabular}


Peserta pelatihan sangat antusias dengan materi ini karena merupakan hal baru yang diketahui mereka.

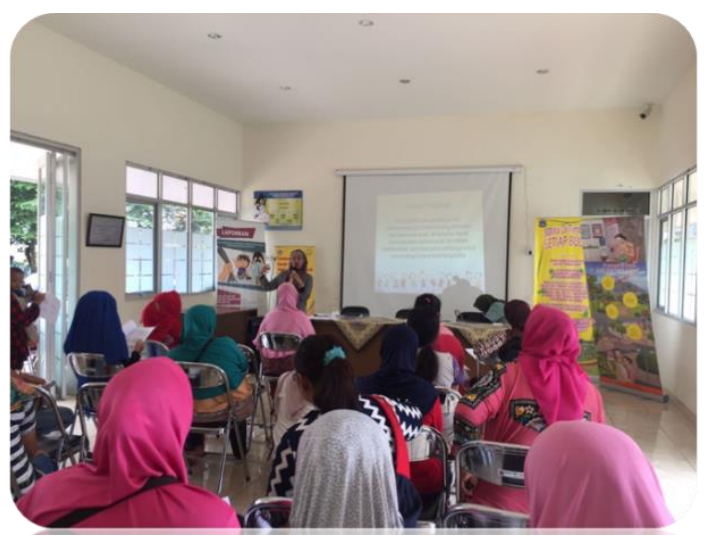

Gambar 2. Pemberian Materi Stimulasi Bermain

\section{Pelatihan keterampilan stimulasi bermain pada balita}

Peserta pelatihan keterampilan stimulasi bermain adalah ibu yang mempunyai balita dan merupakan anggota binaan Bina Keluarga Balita Lili, Mawar dan Melati. Pelatihan ini dibuka oleh perwakilan dari Suku Dinas Pemberdayaan Perlindungan Anak dan Pengendalian Penduduk Jakarta Pusat, dilanjutkan dengan pemberian materi panduan stimulasi bermain. Sebelum pemberian materi dilakukan pemberian pretest untuk mengetahui pengetahuan dasar peserta. Setelah pemberian materi, peserta dilatih untuk melakukan stimulasi bermain dengan alat-alat yang disediakan. Setelah ibu-ibu peserta berlatih, mereka diberi kesempatan untuk mempraktekkan dengan bermain bersama anak-anaknya. Di akhir acara peserta kembali diberikan posttest untuk mengukur peningkatan pengetahuan dan diminta untuk mengisi kuesioner kepuasan. Peserta yang mempunyai peningkatan pengetahuan terbesar diberikan hadiah untuk memotivasi agar tetap semangat menstimulasi anak-anak di rumah.

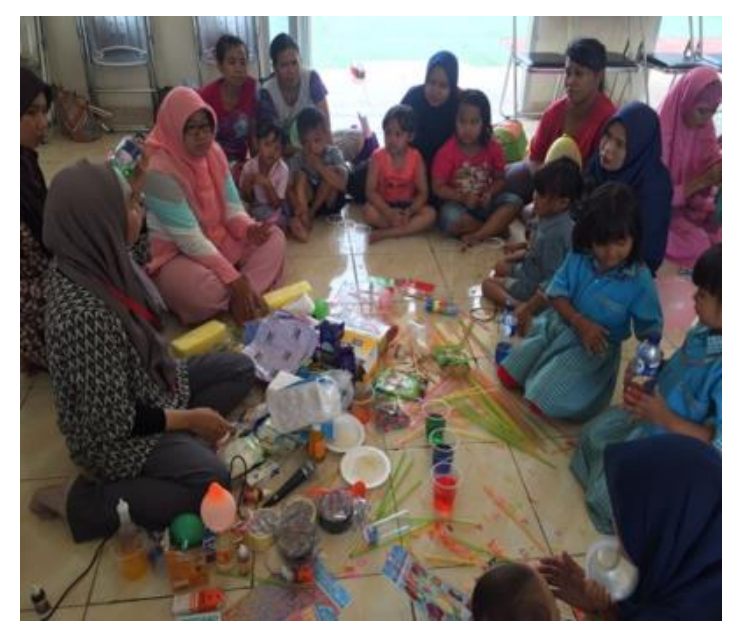

Gambar 3. Pelatihan keterampilan stimulasi bermain 
Peningkatan pengetahuan pada semua peserta diharapkan dapat membantu meningkatkan kemampuan ibu untuk menstimulasi tumbuh kembang balitanya.

Hasil evaluasi didapatkan peningkatan pengetahuan tentang materi panduan stimulasi bermain dilakukan dengan membandingkan nilai pre dan post test. Hasilnya dapat dilihat pada grafik dibawah ini:

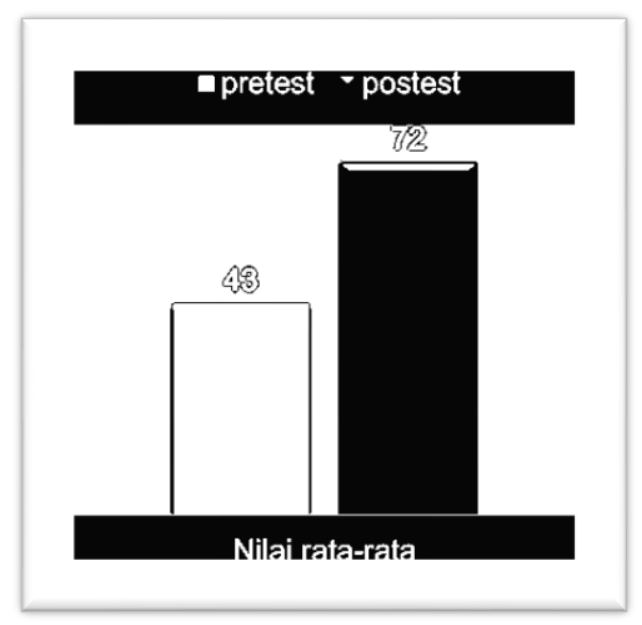

Gambar 4. Perbandingan nilai rata-rata pre dan post test

Berdasarkan grafik diatas terlihat bahwa ada kenaikan nilai rata-rata dari 43 ke 72 . Target pada kegiatan ini adalah peningkatan pengetahuan pada $70 \%$ peserta. Hasilnya semua peserta mengalami peningkatan nilai postest (100\%) seperti terlihat pada grafik dibawah ini:

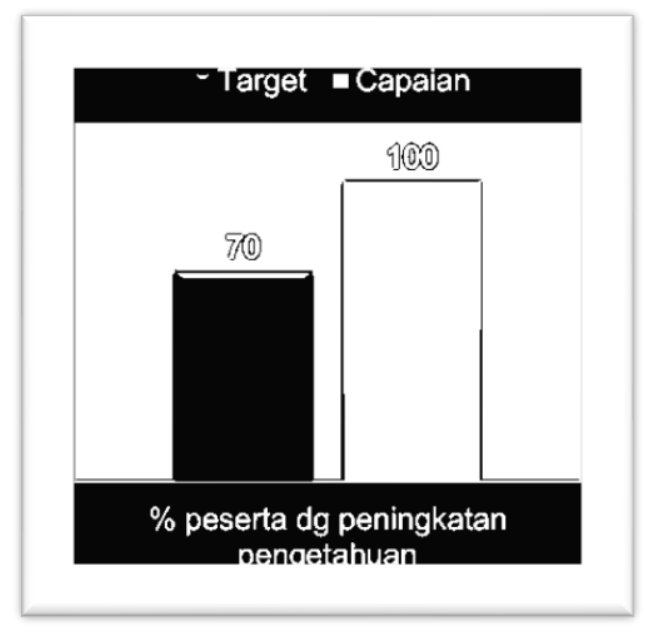

Gambar 5. Prosentase peserta yang mengalami peningkatan pengetahuan

Pemberian stimulasi merupakan domain yang sangat penting dalam membentuk perkembangan seseorang, terbukti bahwa perkembangan yang didasari oleh stimulasi akan lebih cepat terlatih dari pada perkembangan yang tidak didasari oleh stimulasi (Soedjatmiko, 2008).

Dari penelitian yang dilakukan oleh Sunarsih, bahwa stimulasi adalah perangsang yang datang dari lingkungan luar anak. Stimulasi merupakan hal yang sangat penting dalam tumbuh kembang anak. Anak yang yang banyak mendapat stimulasi yang terarah akan lebih cepat berkembang dibandingkan dengan anak yang kurang atau bahkan tidak mendapat stimulasi. Stimulasi juga dapat berfungsi sebagai penguat yang bermanfaat bagi perkembangan anak. Berbagai macam stimulasi seperti stimulasi visual, verbal, audiktif, taktil dan lain-lain. 
Perhatian dan kasih sayang juga merupakan stimulasi yang penting pada awal perkembangan anak, misalnya dengan mengajak bercakap-cakap, membelai, mencium, bermain, dan lain-lain.

Hal tersebut didukung oleh (Siswono.2004) yang menyatakan bahwa rangsangan yang dilakukan sejak dini dan terus menerus akan memacu berbagai aspek perkembangan seperti kecerdasan anak (kecerdasan multipel) yaitu kecerdasan logiko-matematik, emosi, komunikasi bahasa (linguistik), kecerdasan musikal, gerak (kinestik), visuo-spasial, senirupa.

Salah satu cara evaluasi suatu program adalah dengan menilai reaksi peserta. Evaluasi pada kegiatan ini diukur dengan kuesioner kepuasan peserta dengan target 70$\%$ peserta merasa puas. Angka kepuasan peserta pada kegiatan ini dapat dilihat pada grafik dibawah ini:

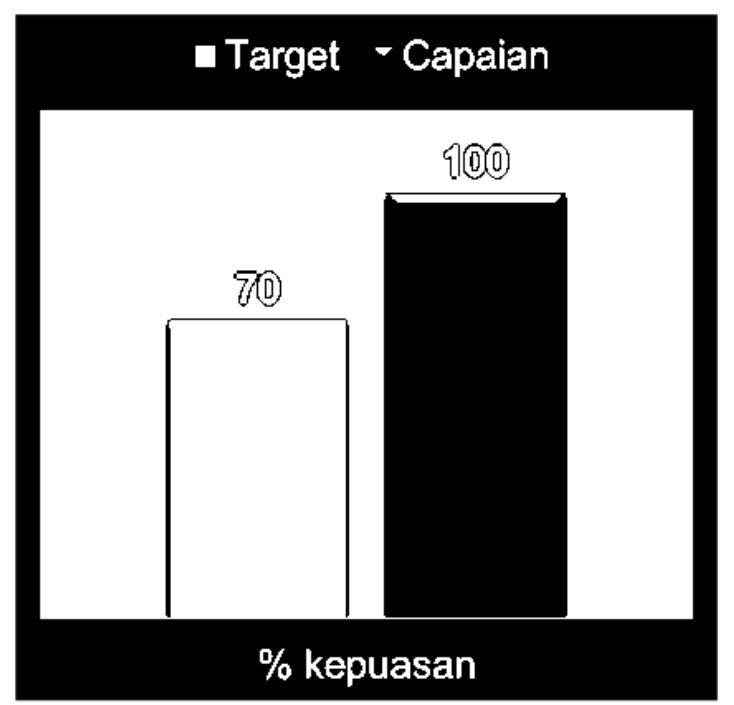

Gambar 6. Angka kepuasan peserta yang melampaui target

Seperti terlihat dari grafik diatas semua peserta merasa puas dengan kegiatan stimulasi bermain bagi balita ini, dari semua peserta yang puas ini juga dapat dilihat tingkat kepuasannya seperti yang terlihat pada pie chart di bawah ini:

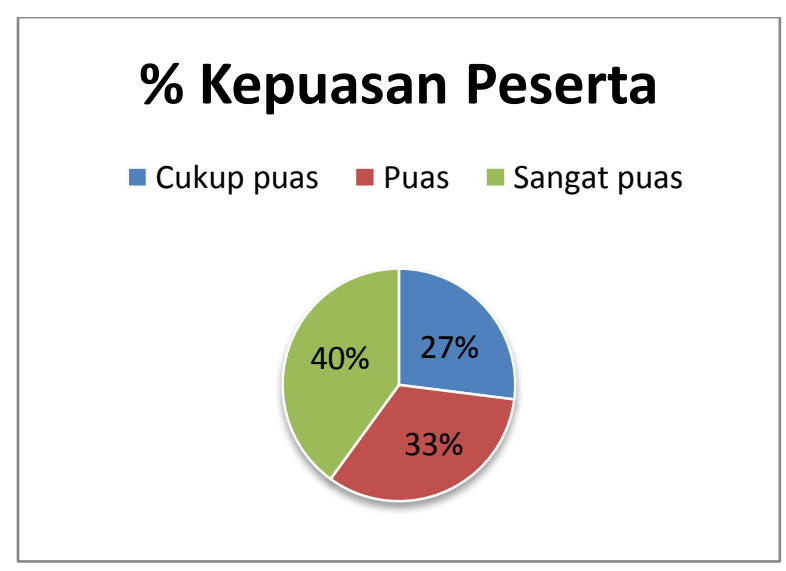

Gambar 7. Angka kepuasan peserta 
Kendala yang dihadapi pada saat persiapan adalah penyediaan alat-alat bermain, karena alat yang dibutuhkan harus disesuaikan dengan stimulasi akan diberikan. Pada roses kegiatan tidak ada kendala karena mitra sangat kooperatif dalam menyiapkan jalannya acara. Kendala lainnya pada tahap evaluasi yaitu pemantauan tindak lanjut yang dilakukan oleh peserta. Untuk kendala pada persiapan, perlunya tambahan tenaga teknis sehingga pada kegiatan ini mahasiswa dilibatkan untuk membantu persiapan. Untuk kendala di evaluasi yaitu pemantauan lanjutan diarahkan kepada kader bina keluarga balita di kelurahan Harapan Mulya, kepada peserta juga diberikan 1 set alat bermain untuk digunakan dirumah sehingga diharapkan dapat melanjutkan kegaitan stimulasi tumbuh kembang bagi balita. Penelitian yang dilakukan oleh Wulandari dan Sari (2016) yang menunjukkan ada pengaruh media bermain terhadap perkembangan anak balita.

\section{Kesimpulan}

1. Adanya peningkatan pengetahuan tentang stimulasi bermain pada balita pada $100 \%$ peserta

2. Angka kepuasan peserta terhadap kegiatan stimulasi bermain pada balita $100 \%$

\section{Saran}

1. Adanya pemantauan dari kader Bina Keluarga Balita untuk kegiatan stimulasi bermain di rumah.

2. RPTRA Harapan Mulya dapat menjadi lokasi yang memfasilitasi kegiatan stimulasi bermain bagi balita di lingkungannya.

\section{Ucapan Terima Kasih}

Penulis mengucapkan terimakasih kepada Lembaga Pemberdayaan Masyarakat Universitas YARSI atas bantuan biaya pada kegiatan pengabdian masyarakat ini, kepada Bagian Ilmu Kesehatan Masyarakat atas bantuan dalam penyusunan buku panduan dan Suku Dinas Pemberdayaan Perlindungan Anak dan Pengendalian Penduduk (PPAPP) Jakarta Pusat.

\section{Daftar pustaka}

Kemenkes RI, 2010. Deteksi dan Intervensi Dini Tumbuh Kembang. Jakarta : Kemenkes RI

Mcwhinney I and Freeman T. 2009. Texbook of Family Medicine $3^{\text {rd }}$ ed. Newyork : Oxford University Press Inc

Pemerintah Daerah Khusus Ibukota Provinsi DKI Jakarta. Pergub No.196 Tahun 2015 tentang Pedoman Pengelolaan RPTRA. Jakarta

Rakhmawati, I, 2015. Peran Keluarga dalam Pengasuhan Anak. Jurnal Bimbingan Konseling Islam, Vol.6, No.1, Juni 2015

Republik Indonesia. 2002. UU No.23 tentang Perlindungan Anak. Sekretariat Negara. Jakarta

Siswono. 2002. Pengantar Perilaku Manusia Untuk Keperawatan . Cetakan Pertama. Jakarta: EGC. 
Soedjtmiko. 2008. Tumbuh Kembang Anak. Jakarta : EGC

Sunarsih T. 2012. Hubungan Antara Pemberian Stimulasi Dini Oleh Ibu Dengan Perkembangam Balita Di Taman Balita Muthia Sido Arum, Sleman Yogyakarta Tahun 2010. E-Journal, journal.respati.ac.id

Wulandari, SR dan Sari,GK. 2016. Pengaruh Media Bermain dengan Perkembangan Anak diukur dengan Denver II pada Anak Usisa Toddler (1-3 Tahun). ejournal.stikesyogyakarta.ac.id/index.php/jksi/article/view/74 